This item is the archived peer-reviewed author-version of:

Bidirectional sun-induced chlorophyll fluorescence emission is influenced by leaf structure and light scattering properties : a bottom-up approach

\title{
Reference:
}

van Wittenberghe Shari, Alonso Luis, Verrelst Jochem, Moreno José, Samson Roeland.- Bidirectional sun-induced chlorophyll fluorescence emission is influenced by leaf structure and light scattering properties : a bottom-up approach

Remote sensing of environment - ISSN 0034-4257 - 158(2015), p. 169-179

DOI: http://dx.doi.org/doi:10.1016/j.rse.2014.11.012

Handle: http://hdl.handle.net/10067/1244070151162165141 


\section{Bidirectional sun-induced chlorophyll fluorescence emission is influenced by leaf structure and light scattering properties-_-A bottom-up approach}

Shari Van Wittenberghe ${ }^{a, *}$

Shari.VanWittenberghe@uantwerpen.bea.ac.be

Luis Alonso $0^{\mathrm{b}}$

Jochem Verrelst ${ }^{\mathrm{b}}$

José Moreno ${ }^{\mathrm{b}}$

Roeland Samson ${ }^{\mathrm{a}}$

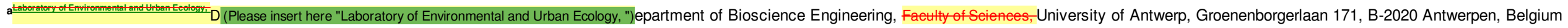

bImage Processing Laboratorył, Department of Earth Physics and Thermodynamics, University of Valencia, C/-Catedrático José Beltrán 2, E-46980 Paternal fValencia, Spain

${ }^{*}$ Corresponding author. Tel.: + 323265 3569; fax: + 3232653225 .

\section{Abstract}

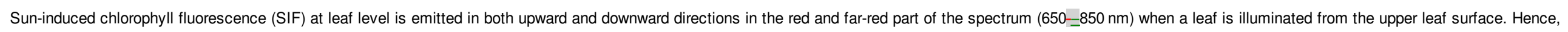

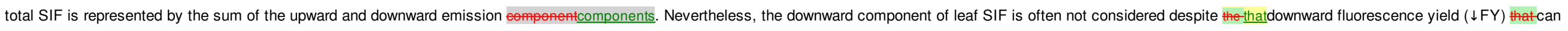

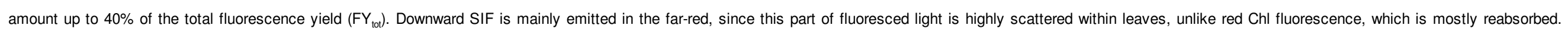

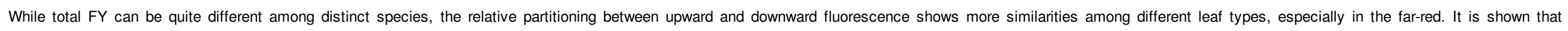

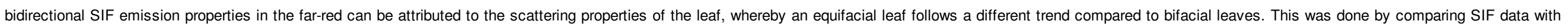

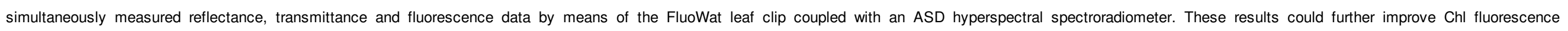
odelling modeling at leaf level, and help to advance the interpretation of SIF at the canopy level.

Keywords: Downward fluorescence; Sun-induced Chl fluorescence; Light absorption; Scattering; Reflectance; Transmittance; Light transfer

\section{Introduction}

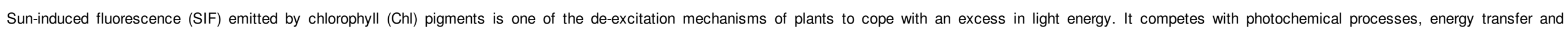

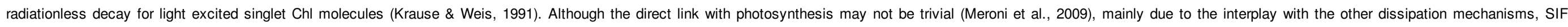

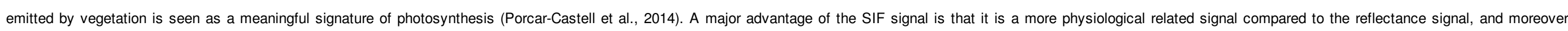

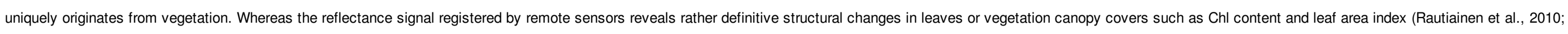
Verrelst, Alonso, Camps-Valls, Delegido, \& Moreno, 2012), SIF represents a more fine-tuned physiological signal with a diurnal dynamic (Amoros-Lopez et al., 2008; Flexas et al., 2002).

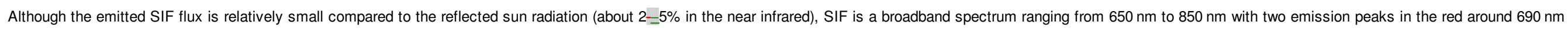

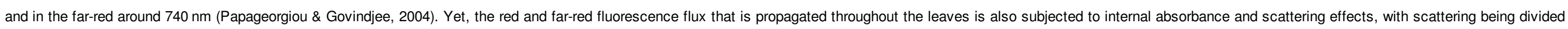

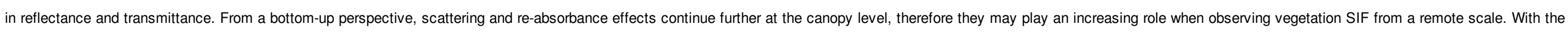

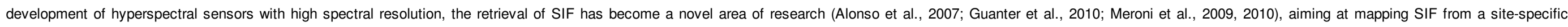

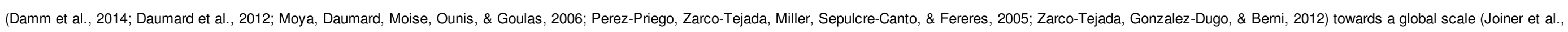




\section{elsevier_RSE_9238}

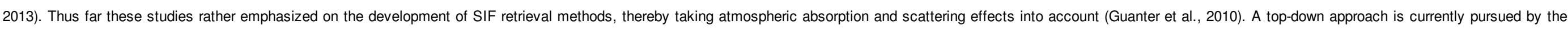

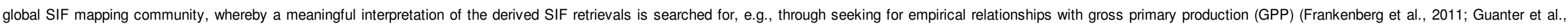

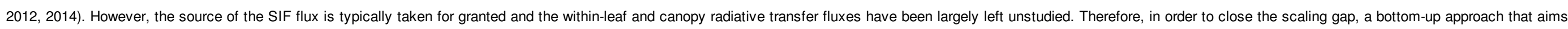

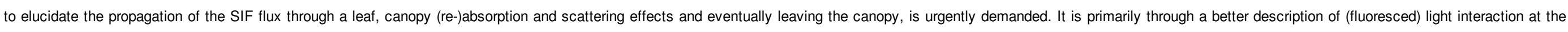
leaf level that will lead to a better interpretation of the remotely retrieved Chl fluorescence signal (Pedrós, Goulas, Jacquemoud, Louis, \& Moya, 2010).

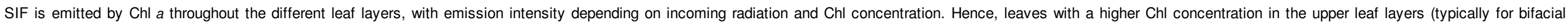

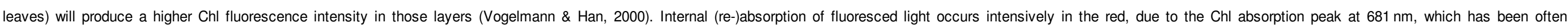

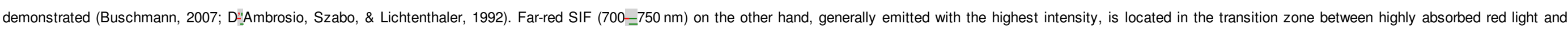

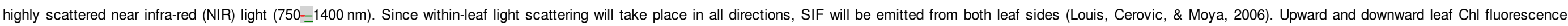

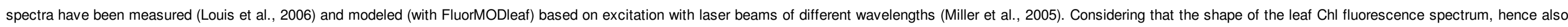

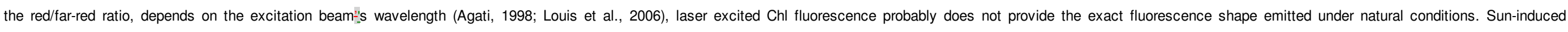

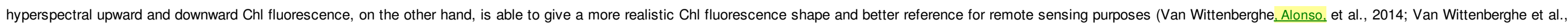
2013).

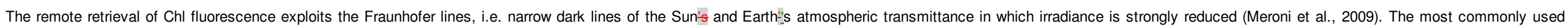

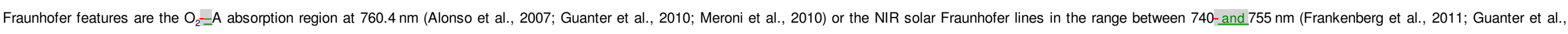

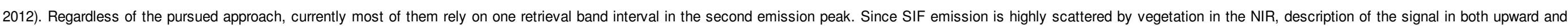

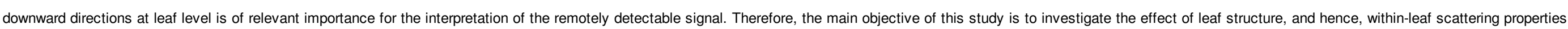

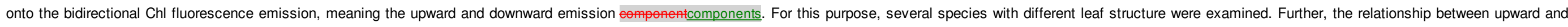

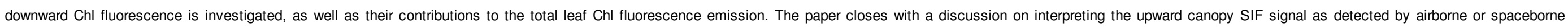
spectrometers.

\section{Materials and methods}

\subsection{Sun-induced reflectance, transmittance and $\mathrm{Chl}$ fluorescence}

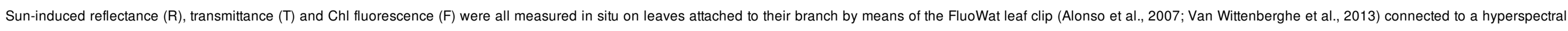

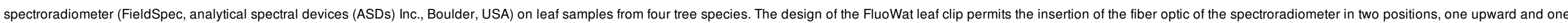

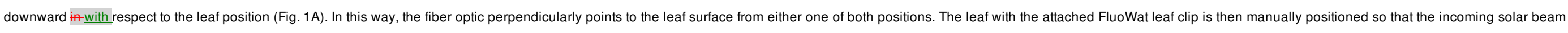

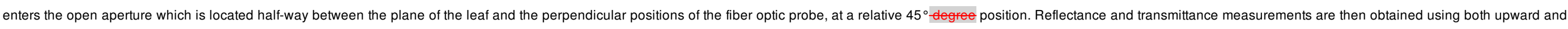

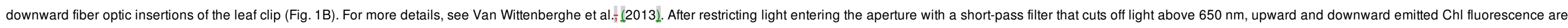

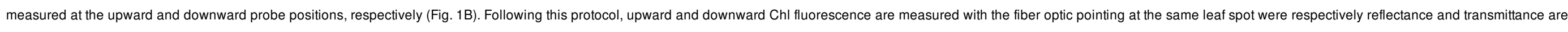
measured, delivering a combined $\mathrm{R}=\mathrm{T}-\mathrm{F}$ F dataset. 

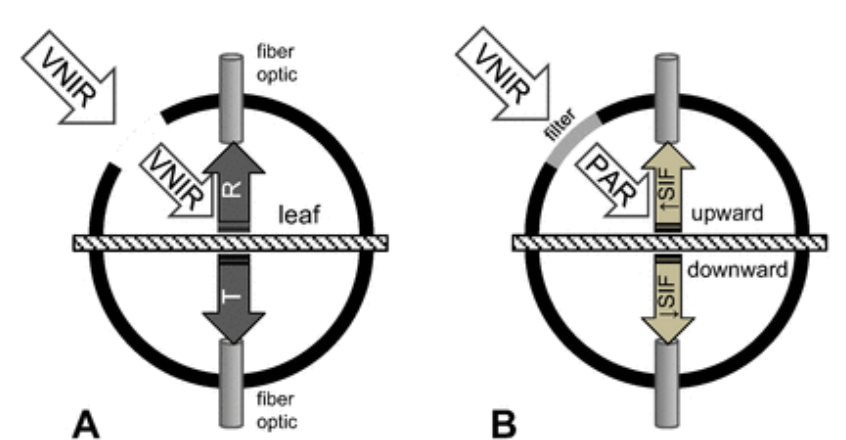

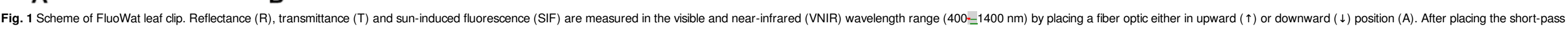
to restrict incoming PAR to visible wavelengths up to $650 \mathrm{~nm}$ (B), upward and downward sun-induced fluorescence ( $\uparrow$ SIF, $\downarrow$ SIF) are measured (after Van Wittenberghe et al., 2013).

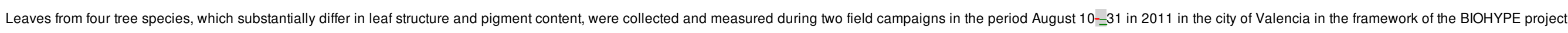

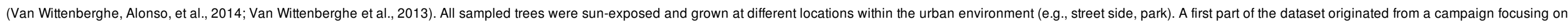

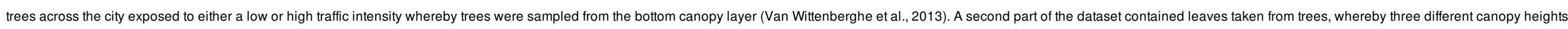

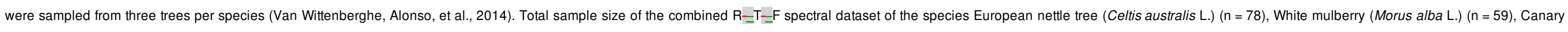

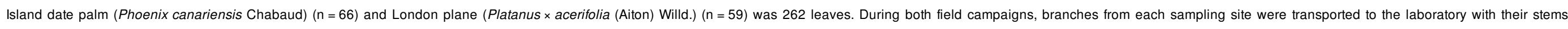

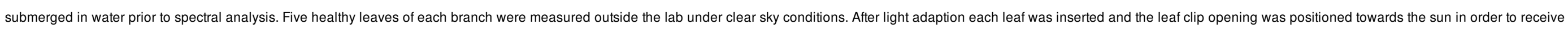
direct sun beams on the leaf surface. Hence, the $R-=T-F$ dataset is obtained with direct sun beams under a $45^{\circ}$ inclination with the leaf surface.

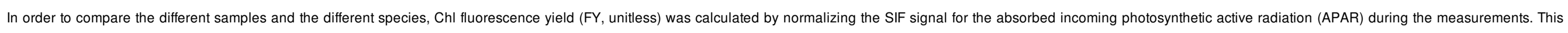

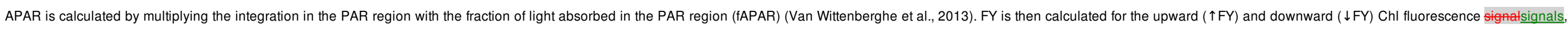

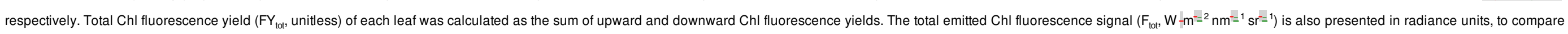

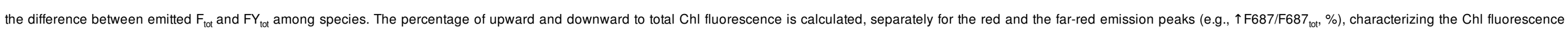

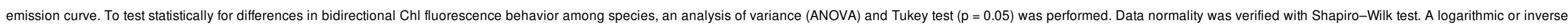
transformation was used when necessary to comply with normality.

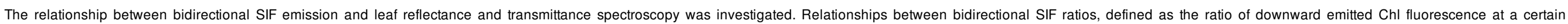

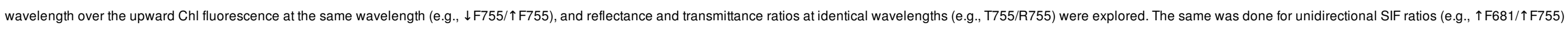

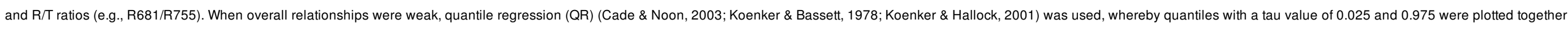
with the median regression $(\tau=0.50$ ). For this analysis, we used the package quantreg in the open-source software R 2.13.0 software (www.r-project.org).

\subsection{Leaf structure and $\mathrm{Chl}$ content}

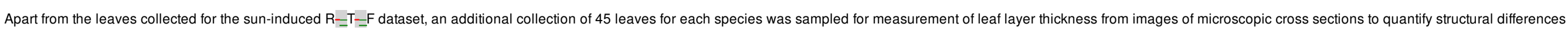

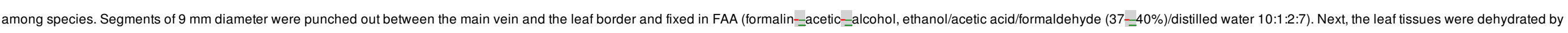

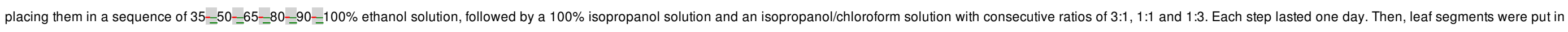

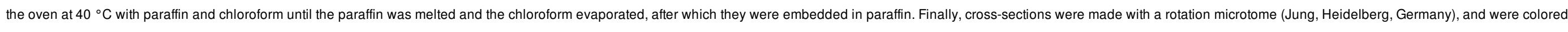

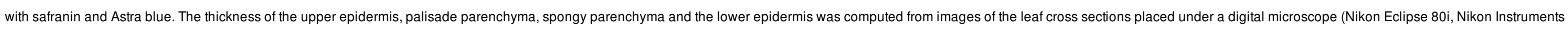

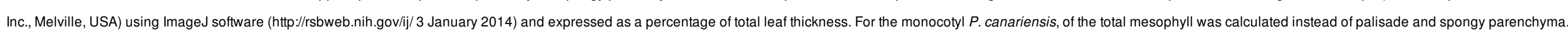

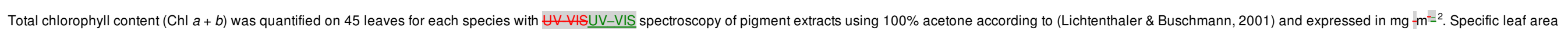




\section{elsevier_RSE_9238}

(SLA) was determined as the ratio of fresh leaf area over dry leaf weight. The latter was determined after drying of leaves at $50-60{ }^{\circ} \mathrm{C}$ for five days in a drying oven. Leaf area was determined on the scanned leaf surface.

\section{Results and discussion}

\subsection{Species" difference in leaf structure}

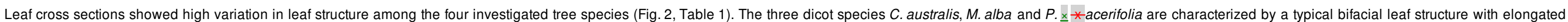

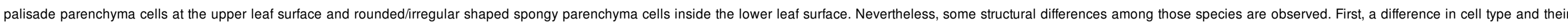

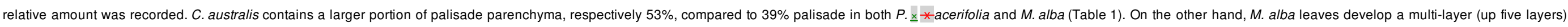

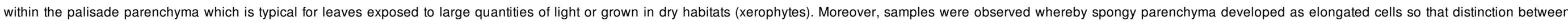

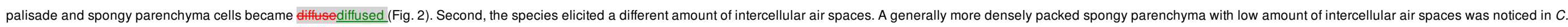
australis and $M$. alba leaves compared to a high amount in $P . \underline{x} *$ acerifolia leaves.
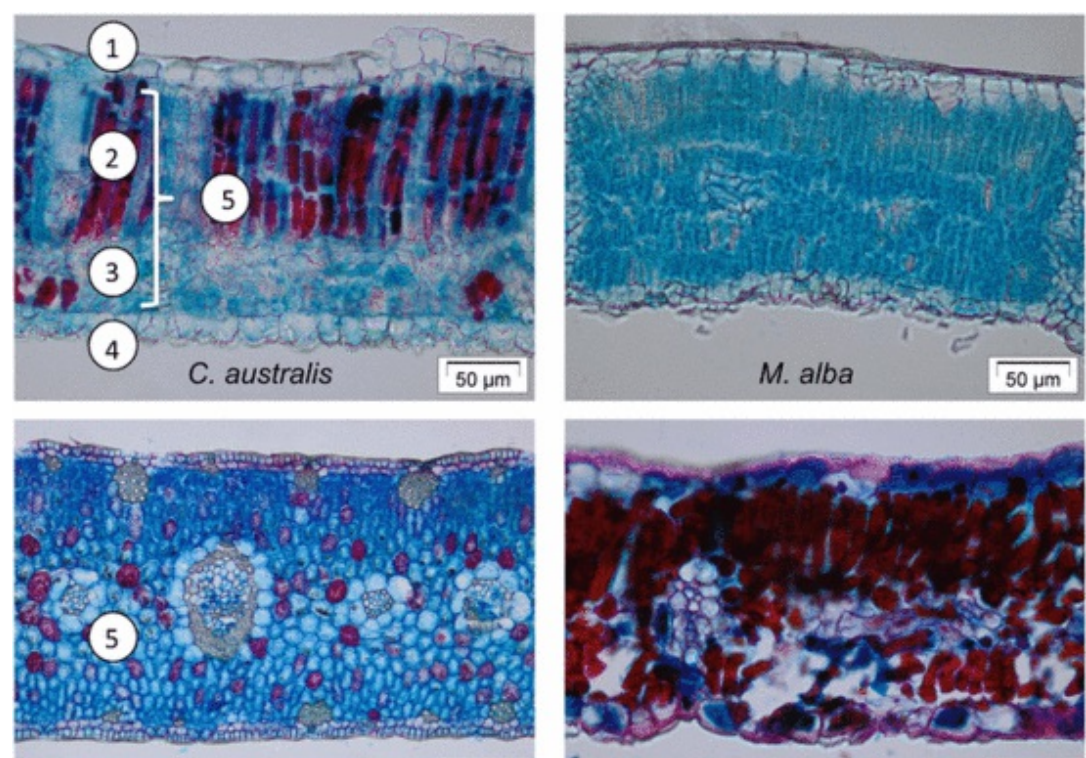

P. canariensis

$\overline{100 \mu \mathrm{m}}$

P. xacerifolia

$\overline{50 \mathrm{~mm}}$

Fig. 2 Leaf cross sections of the four species showing the upper epidermis (1), palisade parenchyma (2), spongy parenchyma (3), lower epidermis (4) and mesophyll (5) layer; note the different scale in the case of the monocot, P. canariensis.

Table 1 Leaf structure description of the four species showing total leaf thickness $(\mu \mathrm{m})$ and the percentage of the different leaf layers (mean \pm standard deviation).

\begin{tabular}{|c|c|c|c|c|}
\hline Species & $P . \underline{x} *$ acerifolia & M. alba & C. australis & P. canariensis \\
\hline Leaf type & Bifacial & Bifacial & Bifacial & Equifacial \\
\hline Total thickness $(\mu \mathrm{m})$ & $185 \pm 21$ & $186 \pm 35$ & $226 \pm 61$ & $396 \pm 36$ \\
\hline Palisade layers ( $\sharp)$ & $1=2$ & $1=5$ & $1=3$ & 0 \\
\hline Amount of intercellular air spaces & High & Low & Low & Low \\
\hline Upper epidermis (\%) & $11 \pm 2$ & $12 \pm 3$ & $10 \pm 3$ & $6 \pm 2$ \\
\hline Mesophyll (\%) & $=$ & $=$ & $=$ & $89 \pm 3$ \\
\hline
\end{tabular}




\begin{tabular}{|c|c|c|c|c|}
\hline Palisade parenchyma (\%) & $39 \pm 5$ & $39 \pm 8$ & $53 \pm 7$ & $=$ \\
\hline Spongy parenchyma (\%) & $38 \pm 5$ & $41 \pm 8$ & $27 \pm 4$ & $=$ \\
\hline Lower epidermis (\%) & $11 \pm 2$ & $8 \pm 2$ & $9 \pm 2$ & $5 \pm 1$ \\
\hline Specific leaf area $\left(\mathrm{cm}^{2} \mathrm{~g}=1\right)$ & $49.2 \pm 7.6$ & $84.9 \pm 20.8$ & $71.2 \pm 19.9$ & $112.4 \pm 19.0$ \\
\hline Chl content $(\mathrm{mg} \mathrm{m}=2)$ & $404 \pm 95$ & $753 \pm 272$ & $888 \pm 142$ & $1244 \pm 279$ \\
\hline
\end{tabular}

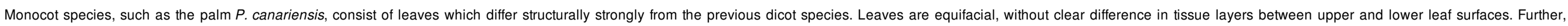
mesophyll cells are densely packed and round-shaped with low amount of intercellular air spaces. Also, palm leaves are twice as thick as the other species! leaves that were examined.

\subsection{Species"- difference in within-leaf light scattering}

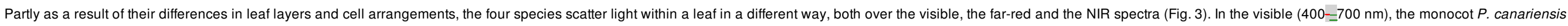

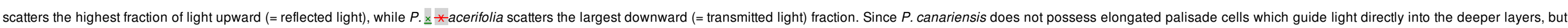

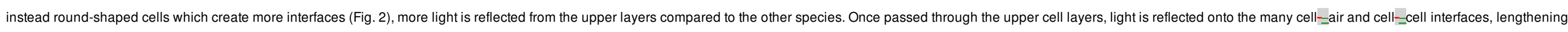

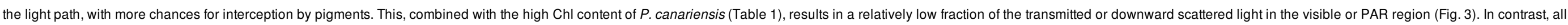
three dicots have thinner leaves, with more intercellular air spaces and lower Chl content (especially $P . \underline{x} *$ acerifolia), resulting in proportionally more downward scattered light which has not been intercepted by Chl (Fig. 3).

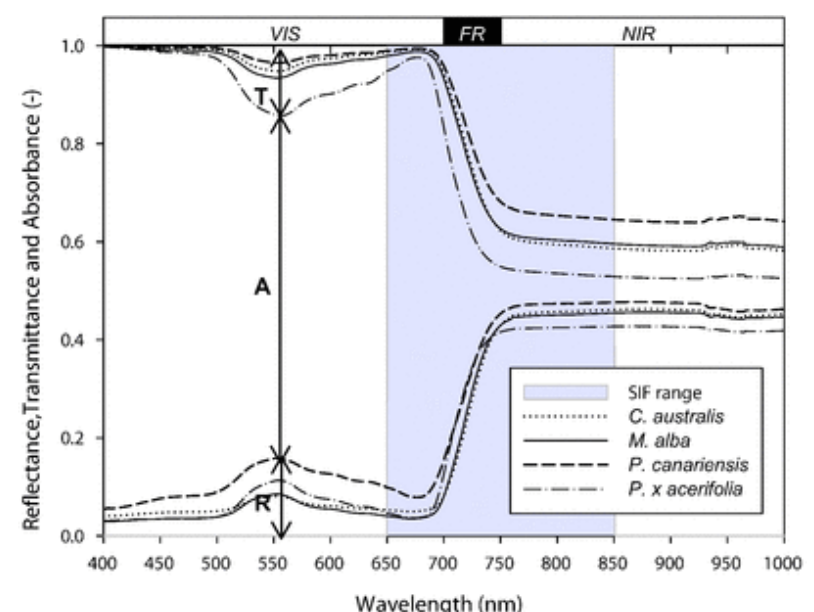

Fig. 3 Average reflectance (R), transmittance (T) and absorbance (A) for the four species in the visible (VIS), far-red (FR) and part of the near-infrared (NIR); sun-induced fluorescence (SIF) is emitted in the indicated shaded spectral area

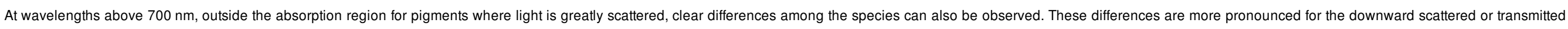

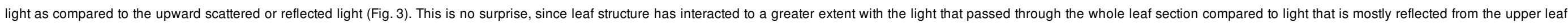

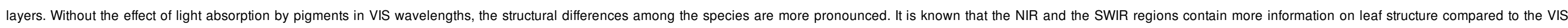

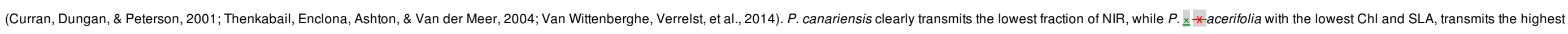

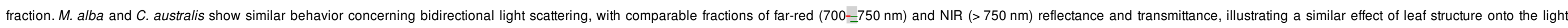

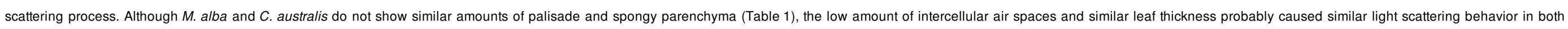
species.

\subsection{Total Chl fluorescence yield and ratios}




\section{elsevier_RSE_9238}

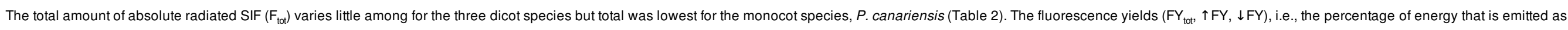

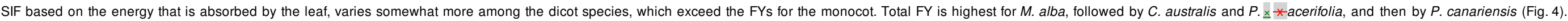

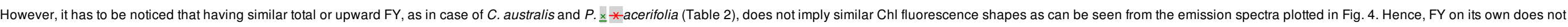
hold all the information. The red/far-red peak ratios indicate better $\mathrm{Chl}$ fluorescence shape differences among species and show statistical differences among the species (Table 2).

Table 2 Tukey test after analysis of variance (ANOVA) for the bidirectional Chl fluorescence behavior among the four species; different small letters indicate significant species differences $(p<0.05)$.

\begin{tabular}{|c|c|c|c|c|}
\hline Species & P. $\underline{x} *$-acerifolia & M. alba & C. australis & P. canariensis \\
\hline $\mathrm{F}_{\text {tot }}\left(\mathrm{W} \mathrm{m}^{-2} \mathrm{~nm}^{-1}=\mathrm{sr}^{-1}\right)$ & $0.120 \pm 0.050 a$ & $0.117 \pm 0.046 a$ & $0.101 \pm 0.032 a$ & $0.068 \pm 0.029 b$ \\
\hline $\mathrm{FY}_{\text {tot }}(\%)$ & $0.269 \pm 0.086 b$ & $0.307 \pm 0.068 \mathrm{a}$ & $0.257 \pm 0.062 b$ & $0.194 \pm 0.051 \mathrm{c}$ \\
\hline$\uparrow \mathrm{FY}(\%)$ & $0.162 \pm 0.054 b$ & $0.204 \pm 0.051 a$ & $0.170 \pm 0.047 \mathrm{~b}$ & $0.130 \pm 0.037 c$ \\
\hline$\downarrow F Y(\%)$ & $0.107 \pm 0.034 a$ & $0.103 \pm 0.023 a$ & $0.087 \pm 0.019 b$ & $0.065 \pm 0.016 c$ \\
\hline$\uparrow F Y / F Y_{\text {tot }}(\%)$ & $60.0 \pm 3.1 b$ & $66.2 \pm 4.8 \mathrm{a}$ & $65.9 \pm 3.7 \mathrm{a}$ & $66.5 \pm 4.0 \mathrm{a}$ \\
\hline$\downarrow F F_{/ F} Y_{\text {tot }}(\%)$ & $40.0 \pm 3.1 \mathrm{a}$ & $33.8 \pm 4.8 \mathrm{~b}$ & $34.1 \pm 3.7 \mathrm{~b}$ & $33.5 \pm 4.0 \mathrm{~b}$ \\
\hline$\uparrow$ F687/F687 & $65.1 \pm 5.2 \mathrm{c}$ & $81.8 \pm 6.1 b$ & $84.3 \pm 4.6 b$ & $87.9 \pm 7.6 a$ \\
\hline$\uparrow F 741 / F^{2} 41_{\text {tot }}(\%)$ & $58.6 \pm 2.6 b$ & $61.7 \pm 4.3 a$ & $61.1 \pm 3.0 \mathrm{a}$ & $59.0 \pm 3.4 b$ \\
\hline$\uparrow F 687 / \uparrow F 741$ & $0.93 \pm 0.33 a$ & $0.65 \pm 0.08 b$ & $0.50 \pm 0.07 c$ & $0.75 \pm 0.23 b$ \\
\hline$\downarrow F 687 / \downarrow F 741$ & $0.76 \pm 0.41 a$ & $0.24 \pm 0.10 \mathrm{~b}$ & $0.15 \pm 0.04 c$ & $0.18 \pm 0.20 \mathrm{bc}$ \\
\hline $\mathrm{F} 687_{\text {tol }} / \mathrm{F} 741_{\text {tot }}$ & $0.86 \pm 0.36 a$ & $0.49 \pm 0.09 b$ & $0.37 \pm 0.05 c$ & $0.51 \pm 0.20 \mathrm{~b}$ \\
\hline
\end{tabular}

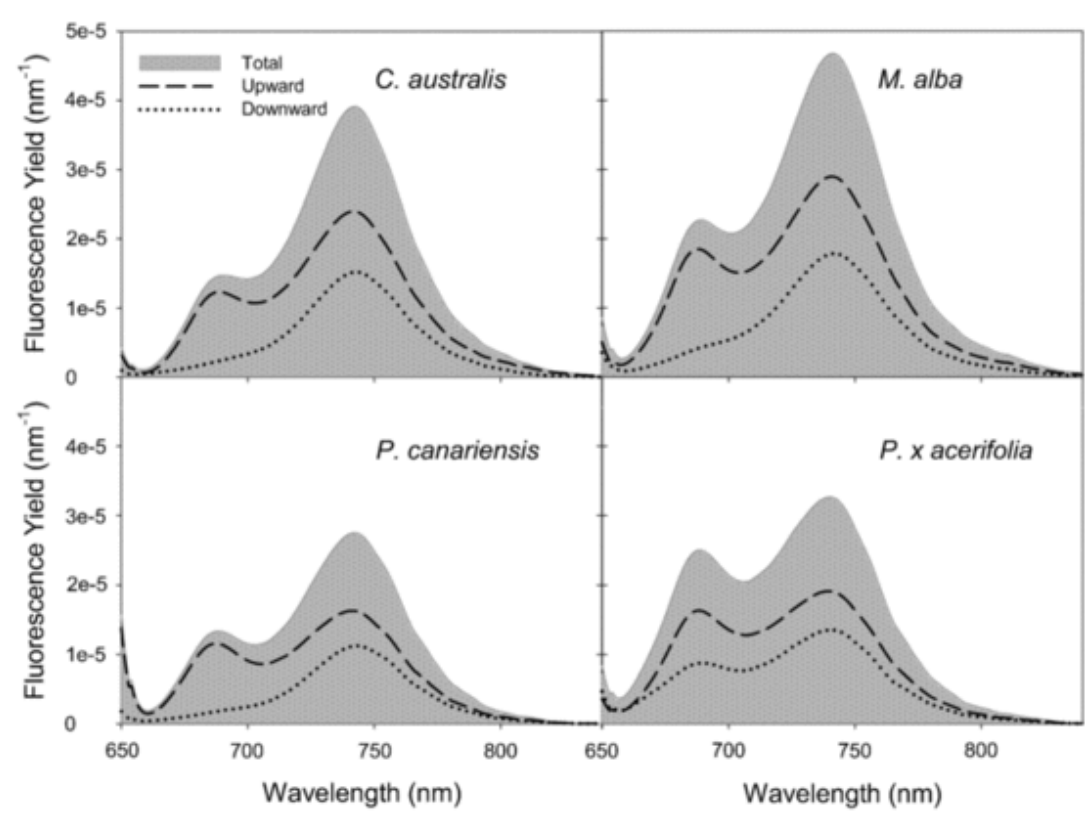

Fig. 4 Typical individual leaf level total (shaded area) as well as upward (dashed curves) and downward (dotted curves) Chl fluorescence tiett-yields for the four species. 


\section{elsevier_RSE_9238}

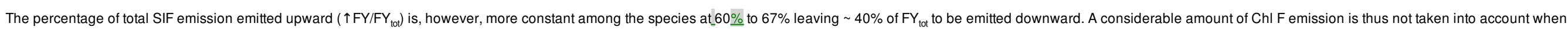

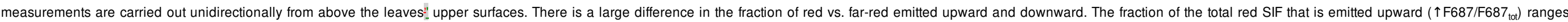
between $65.1 \%\left(P . \underline{*} *\right.$ acerifolia) and $87.9 \%$ (P. canariensis). However, the fraction of the total far-red SIF emitted upward ( $\uparrow F 741 / F 741_{\text {tot }}$ ) is more similar $(\sim 61 \%)$ among the different species.

\subsection{Relationship between upward, downward and total Chl fluorescence}

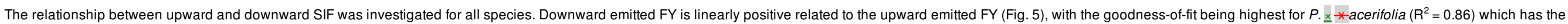

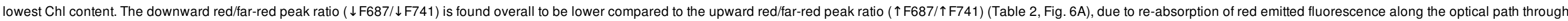

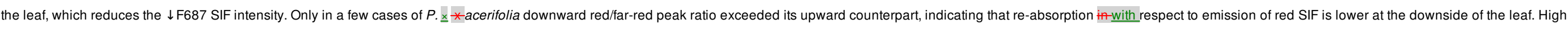

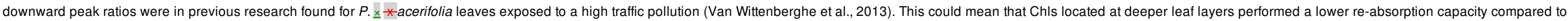

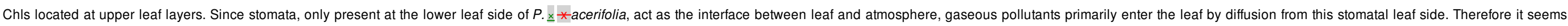
evident that the first place of less-functioning $\mathrm{Chl}$ due to air pollutants happens at the leaf interior: lower part.

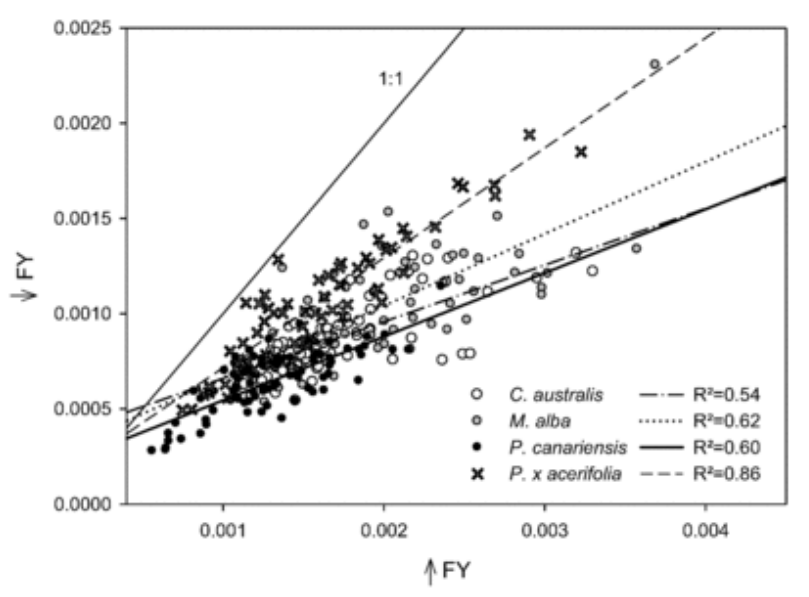

Fig. 5 Linear regression between upward $\mathrm{Chl}$ fluorescence yield $(\uparrow F Y)$ and downward $\mathrm{Chl}$ fluorescence yield $(\downarrow \mathrm{FY})$ with the coefficient of determination $\left(\mathrm{R}^{2}\right)$ for the four species.
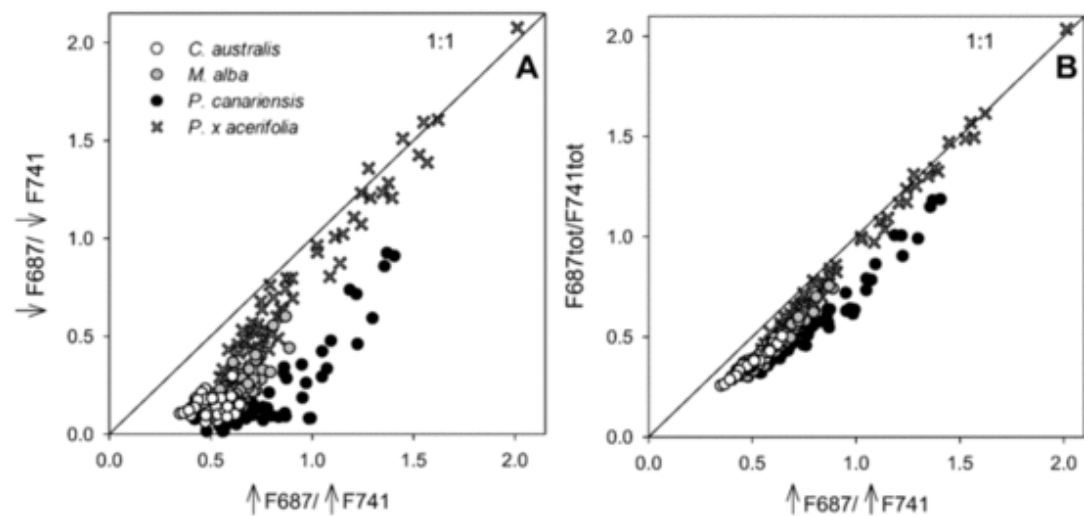

Fig. 6 Comparison of the red/far-red peak ratios for upward $(\uparrow)$ and downward ( $\downarrow$ ) Chl fluorescence emission emissions (A) and upward and total Chl fluorescence emission emissions (B)

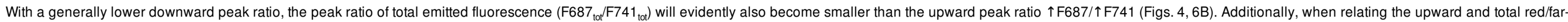

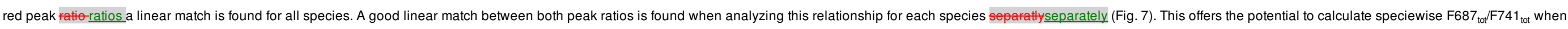




\section{elsevier_RSE_9238}

only $\uparrow F 687 / \uparrow F 741$ is known.
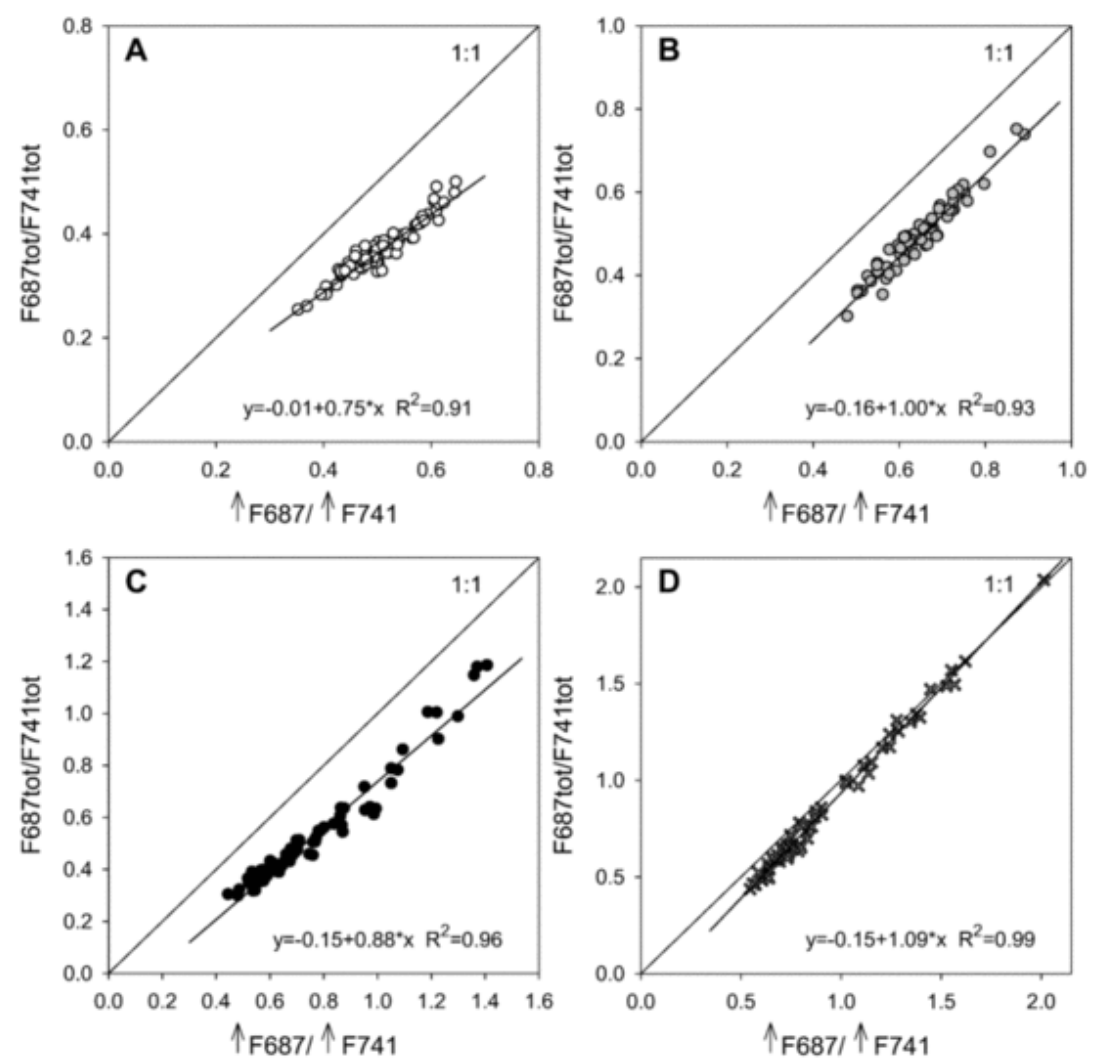

Fig. 7 Linear relationship between upward ( $\uparrow$ ) and total (tot) red/far-red peak ratios for $C$. australis (A), M. alba (B), P. canariensis (C) and $P$. $x$ * *acerifolia (D). Scales vary for each panel, A-D.

\subsection{Re-absorption and scattering effects onto bidirectional Chl F emission}

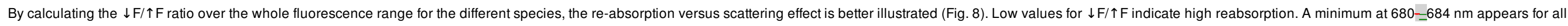

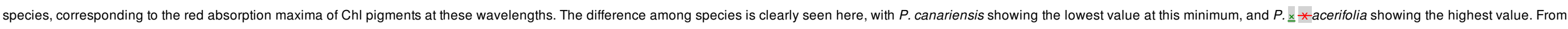

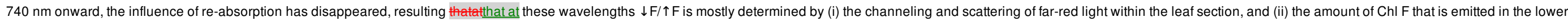

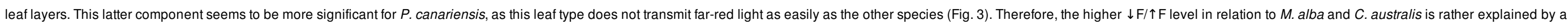

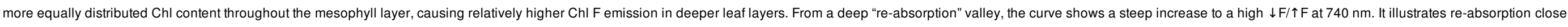
to the 680 maximum taking place until the deeper leaf layers, while Chl F emission is still emitted from these layers in case of the thick palm leaves. 


\section{elsevier_RSE_9238}

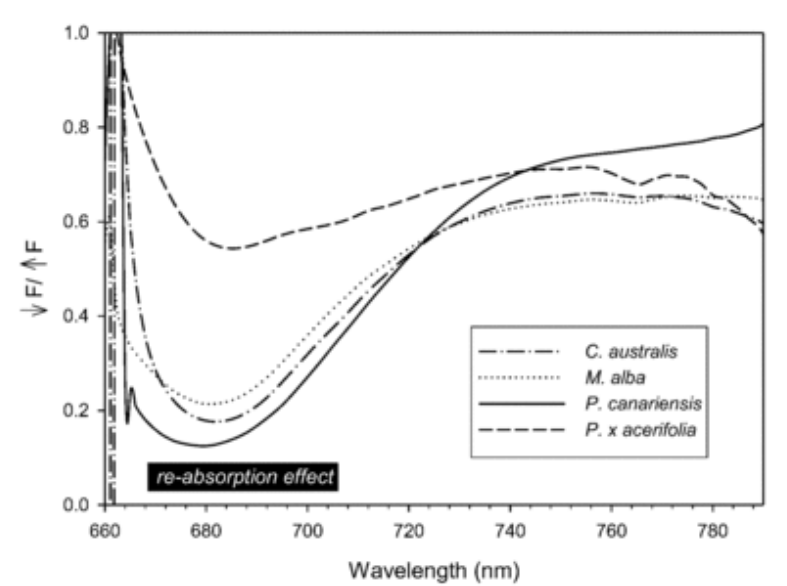

Fig. 8 Downward to upward ratio for the $\mathrm{Chl}$ fluorescence spectrum ( $\downarrow F / \uparrow F)$ for the four species.

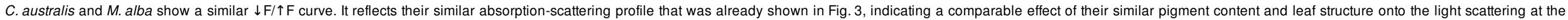

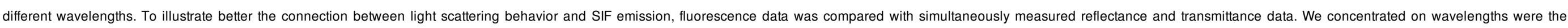
absorption effect (at $681 \mathrm{~nm}$, corresponding with the absorption maximum in the red) and scattering effect (at $755 \mathrm{~nm}$, outside the re-absorption influence) were high.

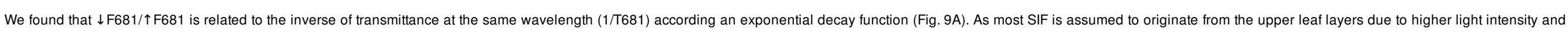

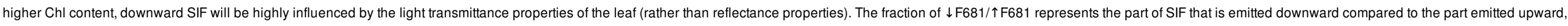

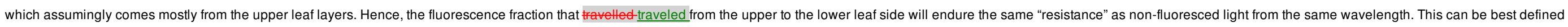
by the transmittance at the same wavelength. Moreover, by taking the inverse T681, the 'extinction effect' due to re-absorption is better described. 


\section{elsevier_RSE_9238}
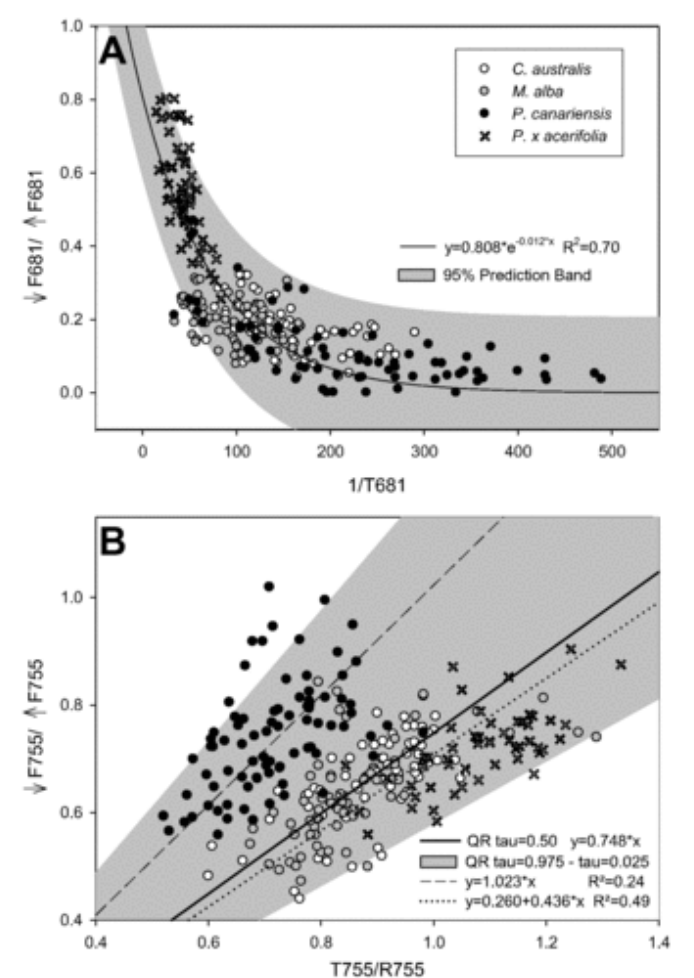

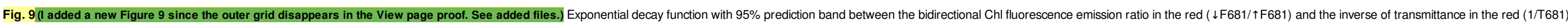

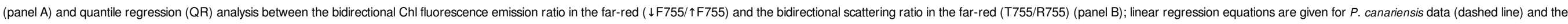
group of C. australis, M. alba and P. $\underline{x} *$ *acerifolia (dotted line)!

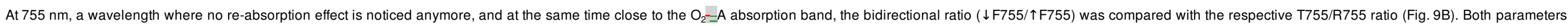

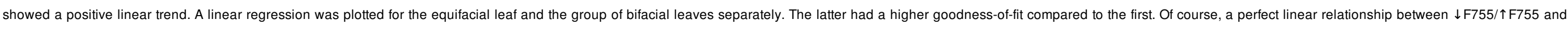

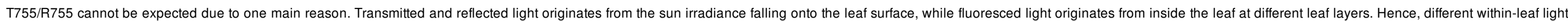

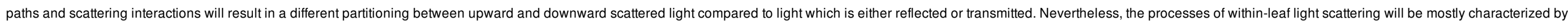
its leaf structure, resulting in a positive trend between both ratios. For describing a general variation trend, quantile regression (QR) was used, showing a wider variation the higher both parameters.

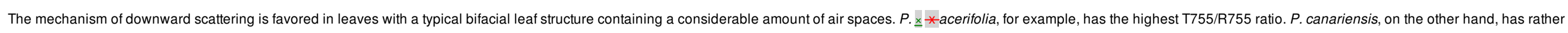
low T755/R755 values. For the same T755/R755 ratio, the palm tree has a higher $\downarrow F 755 / \uparrow F 755$ ratio compared to the bifacial leaf types, which might indicate that relatively more Chl fluorescence is emitted from the lower leaf layers.

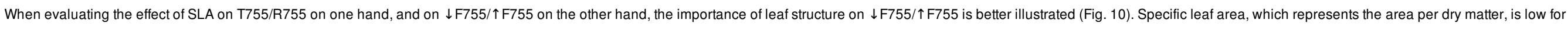

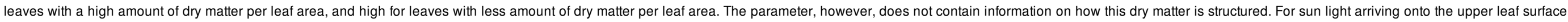

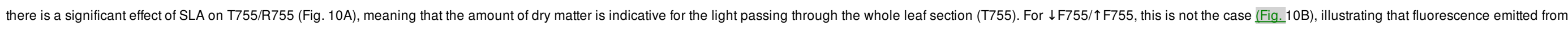
the leaf interior will be also influenced by other factors such as location of emission (pigments) and leaf structure. 


\section{elsevier_RSE_9238}
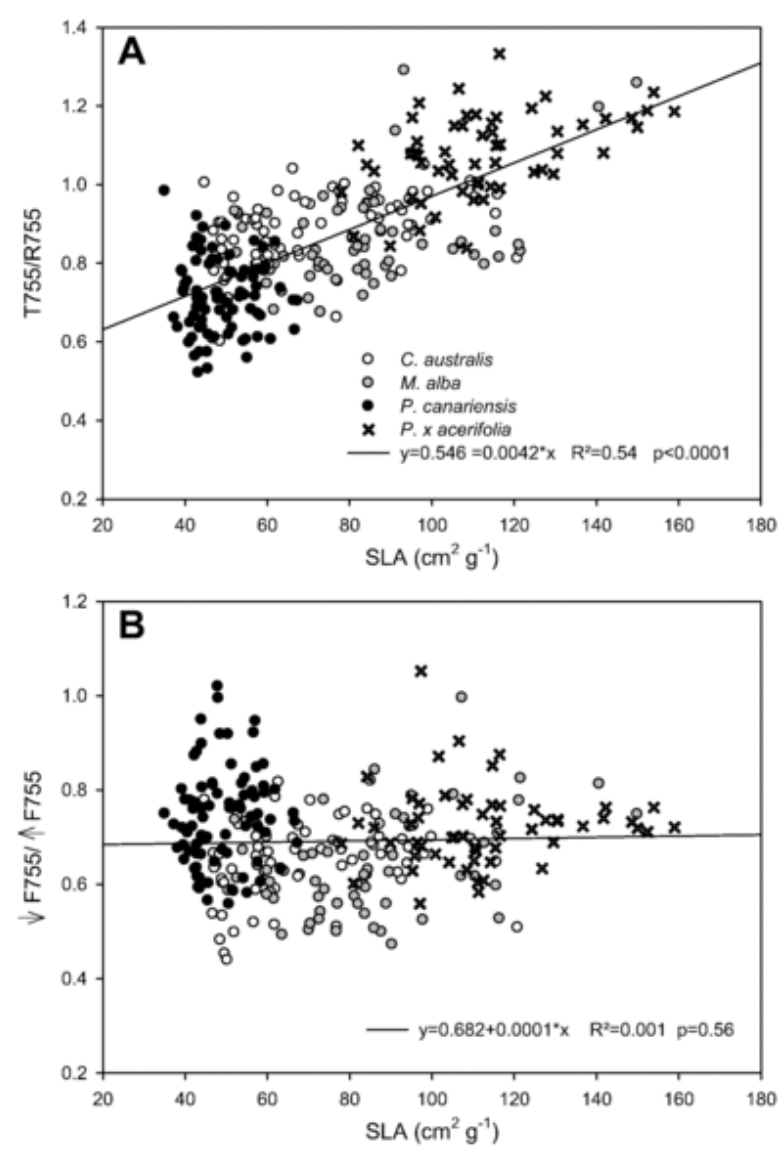

Fig. 10 Linear effect of specific leaf area (SLA) on T755/R755 (panel A) and on $\downarrow F 755 / \uparrow F 755$ (panel B)

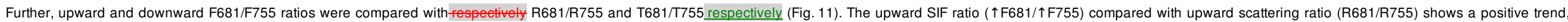

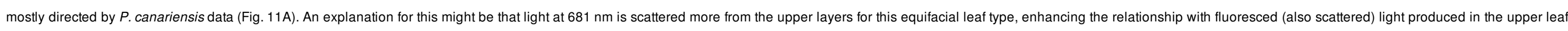

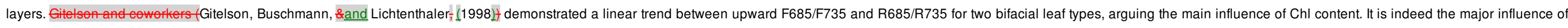

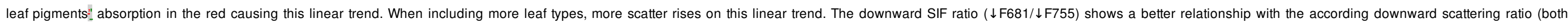
parameters are presented as their inverse for a better fitted relationship), which is explained by a larger influence of leaf spectroscopy, hence absorbance by pigments, onto the downward SIF signal. 

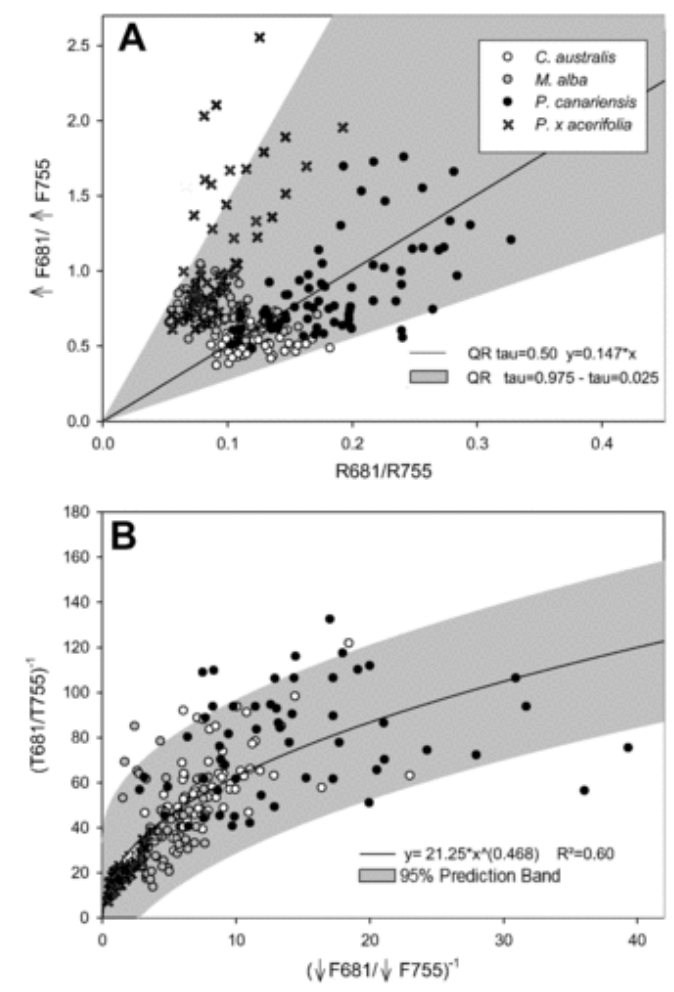

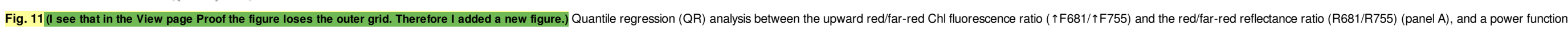
and corresponding $95 \%$ prediction band plotted between the downward inverse red/far-red $\mathrm{Chl}$ fluorescence peak ratio and the corresponding transmittance ratio (panel B)!

\subsection{Consequences for remote signal of Chl fluorescence}

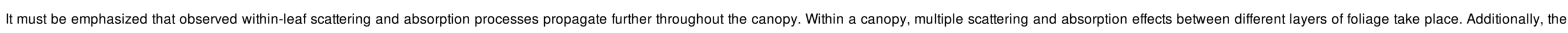

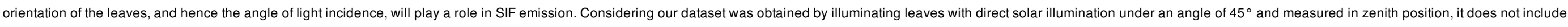

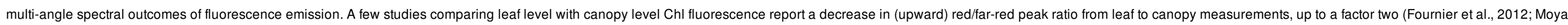

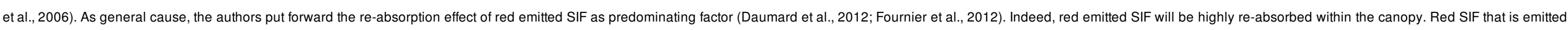

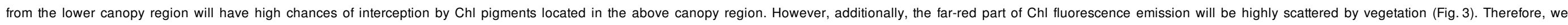
hypothesize that both systematical multiple re-absorption and scattering effects will cause decreasing of the red/far-red peak ratio at canopy level as compared to the leaf level.

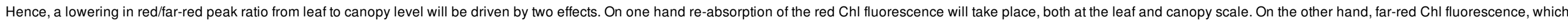

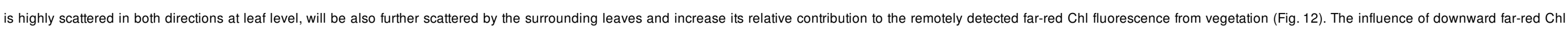

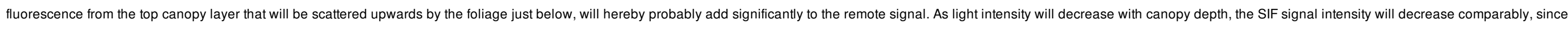

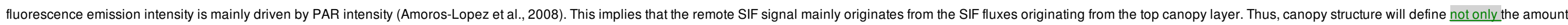

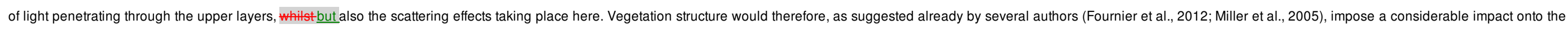
canopy $\mathrm{Chl}$ fluorescence detected from a remote platform. 


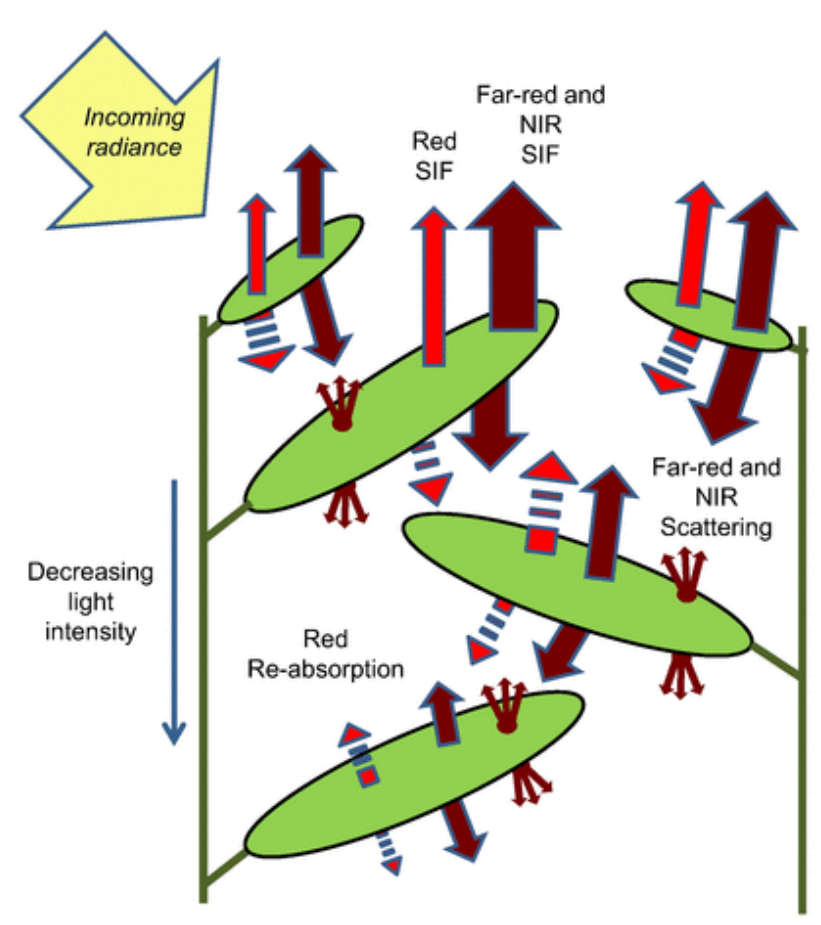

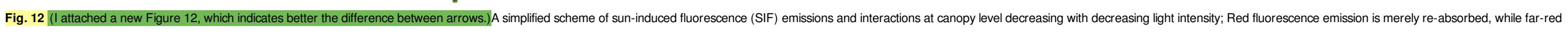
and near-infrared (NIR) fluorescence emission is scattered up- and downward. (For interpretation of the references to color in this figure legend, the reader is referred to the web version of this article.). (In fact, the figure is readible in black and white too.)

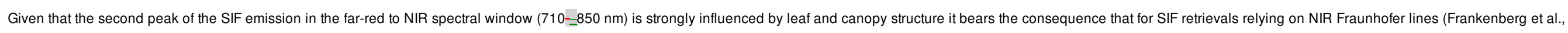

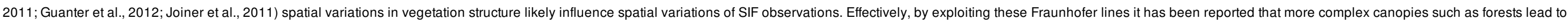

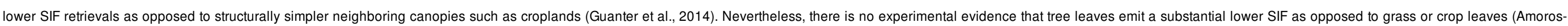

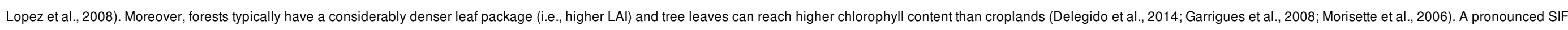

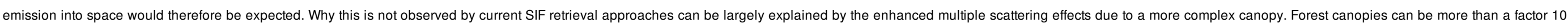

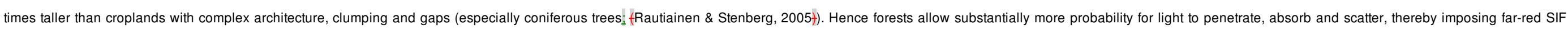

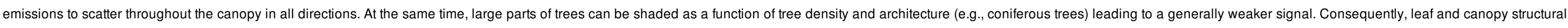

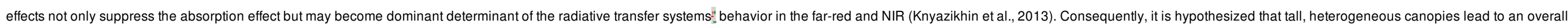
more hemispherically scattered SIF flux in the far-red and NIR, and therefore relatively lower at-sensor SIF intensity as opposed to more homogeneous and structurally simpler canopies.

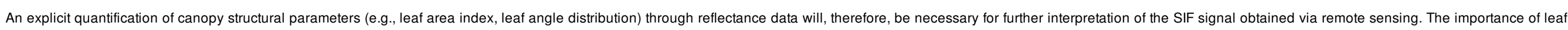

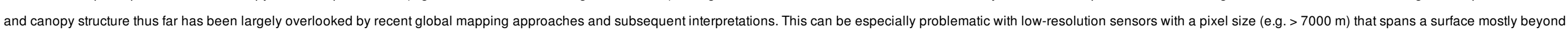

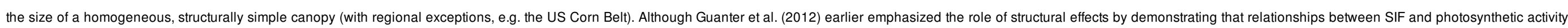

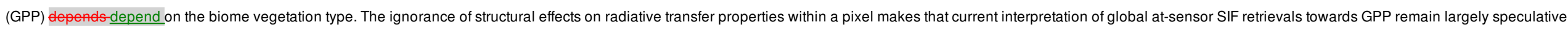

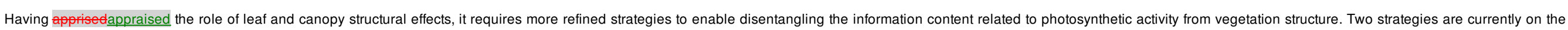

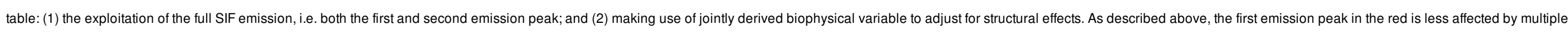

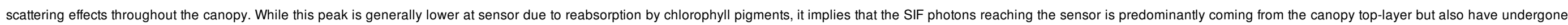

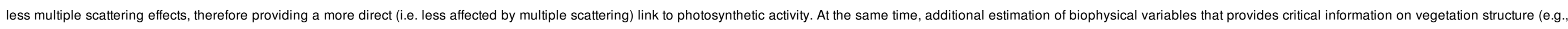




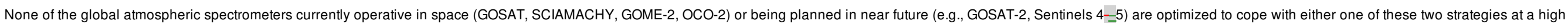

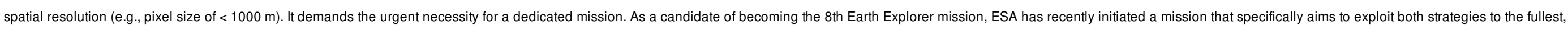

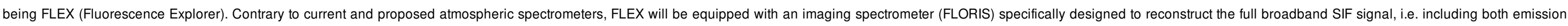

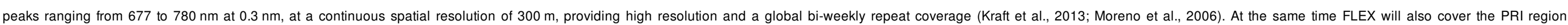

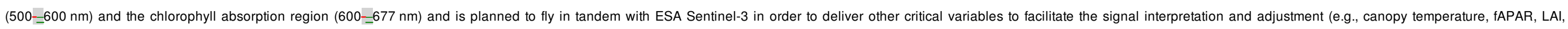

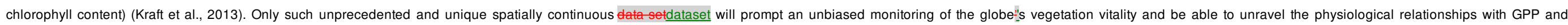
photosynthetic carbon uptake.

\section{Conclusions}

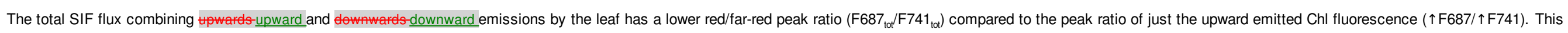

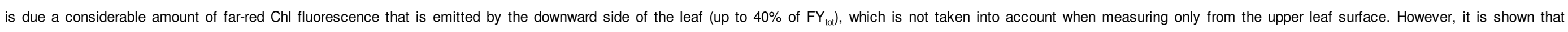
$\mathrm{F} 687_{\text {tot }} / \mathrm{F} 741_{\text {tot }}$ can be estimated from $\uparrow F 687 / \uparrow F 741$ with good accuracy at species level.

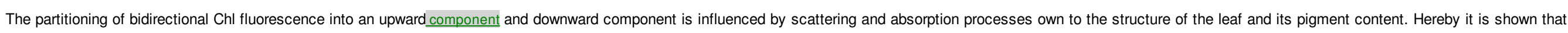

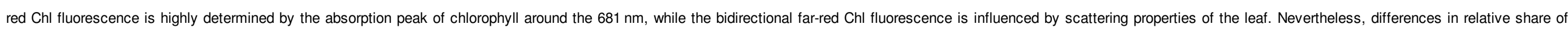
upward or downward $\mathrm{Chl}$ fluorescence in the total amount (e.g., $\downarrow \mathrm{FY} / \mathrm{FY}$ tot $)$ are quite small among species.

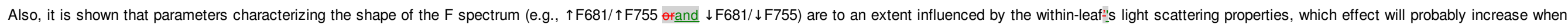

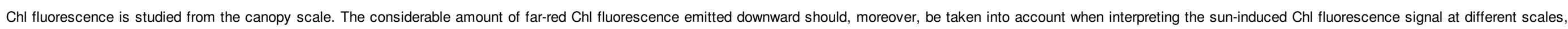

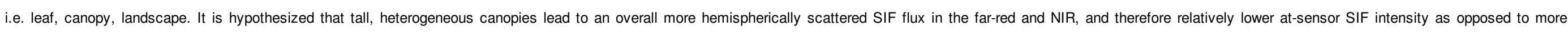
homogeneous and structurally simpler canopies.

\section{AcknowledgementsAcknowledgments}

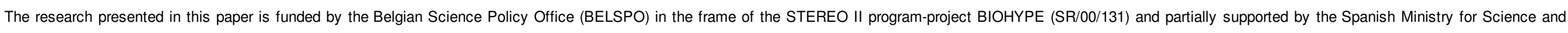

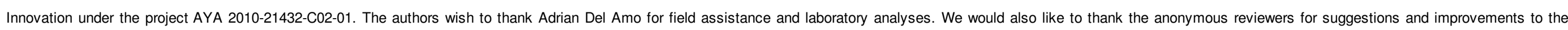
manuscript, and Luis Guanter for adding useful comments on the upscaling section.

\section{References}

Agati G., Response of the in vivo chlorophyll fluorescence spectrum to environmental factors and laser excitation wavelength, Pure and Applied Optics 7, $1998,797-807$.

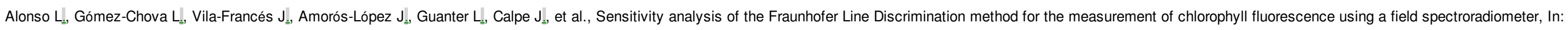

Proceedings of the 3th3rd International Workshop on Remote Sensing of Vegetation Fluorescence, Florence, Italy, 2007, (7-_9 February).

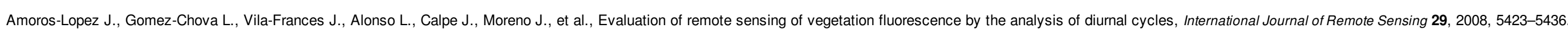
Buschmann C., Variability and application of the chlorophyll fluorescence emission ratio red/far-red of leaves, Photosynthesis Research 92, 2007, 261-271.

Cade B.S. and Noon B.R., A gentle introduction to quantile regression for ecologists, Frontiers in Ecology and the Environment 1, $2003,412-420$.

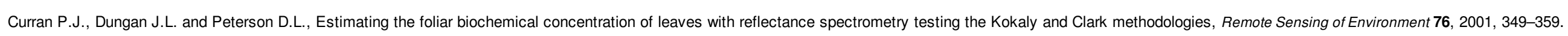

Din Ambrosio N., Szabo K. and Lichtenthaler H.K., Increase of the chlorophyll fluorescence ratio F690/F735 during the autumnal chlorophyll breakdown, Radiation and Environmental Biophysics 31, $1992,51-62$. 


\section{elsevier_RSE_9238}

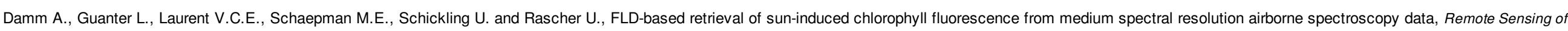
Environment 256-266, 2014.

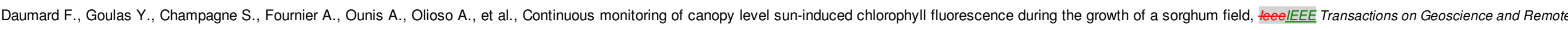
Sensing 50, 2012, 4292-4300.

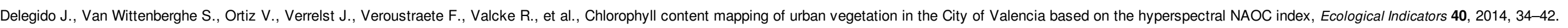

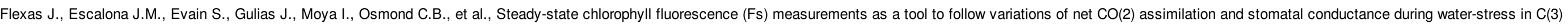
plants, Physiologia Plantarum 114, 2002, 231-240.

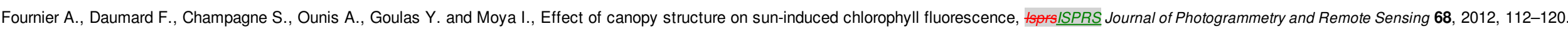

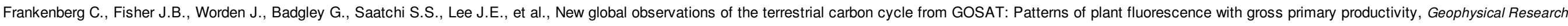
Letters 38, 2011.

Garrigues S., Lacaze R., Baret F., Morisette J.T., Weiss M., Nickeson J.E., et al., Validation and intercomparison of global Leaf Area Index products derived from remote sensing data, Journal of Geophysical Research-_Biogeosciences 113, 2008, http://dx.doi.org/10.1029/2003GB002199.

Gitelson A.A., Buschmann C. and Lichtenthaler H.K., Leaf chlorophyll fluorescence corrected for re-absorption by means of absorption and reflectance measurements, Journal of Plant Physiology 152, 1998, 283-296.

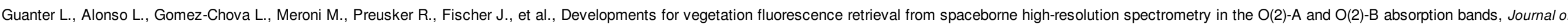
Geophysical Research-_Atmospheres 115, 2010.

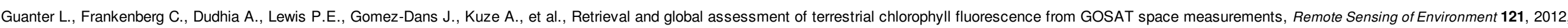
236-251.

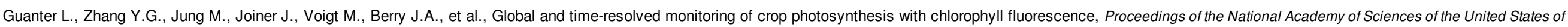
America 111, 2014, E1327-E1333.

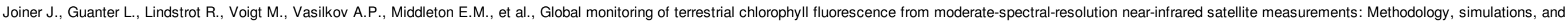
application to GOME-2, Atmospheric Measurement Techniques 6, 2013, 2803-2823.

Joiner J., Yoshida Y., Vasilkov A.P., Yoshida Y., Corp L.A. and Middleton E.M., First observations of global and seasonal terrestrial chlorophyll fluorescence from space, Biogeosciences 8, $2011,637-651$.

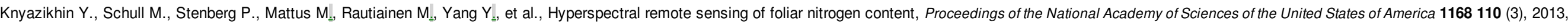
811-812, (E185-E192).

Koenker R. and Bassett G., Regression quantiles, Econometrica 46, 1978, 33-50.

Koenker R. and Hallock K.F., Quantile regression, Journal of Economic Perspectives 15, 2001, 143-156.

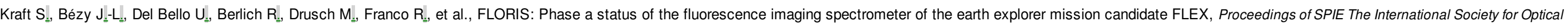
Engineering 2013, 8889.

Krause G.H. and Weis E., Chlorophyll fluorescence and photosynthesis-_-The basics, Annual Review of Plant Physiology and Plant Molecular Biology 42, 1991, 313-349.

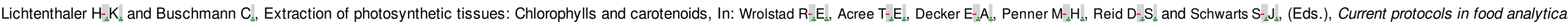
chemistry, 2001, John Wiley and Sons; New York, F4.2.1-F4.2.6. 


\section{elsevier_RSE_9238}

Louis J., Cerovic Z.G. and Moya I., Quantitative study of fluorescence excitation and emission spectra of bean leaves, Journal of Photochemistry and Photobiology B--Biology 85, $2006,65-71$.

Meroni M., Busetto L., Colombo R., Guanter L., Moreno J. and Verhoef W., Performance of spectral fitting methods for vegetation fluorescence quantification, Remote Sensing of Environment 114, 2010, 363-374.

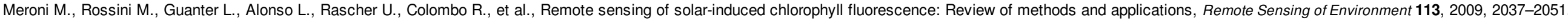

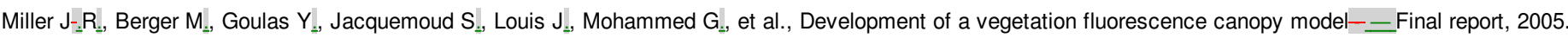

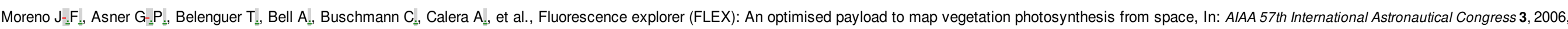
2065-2074.

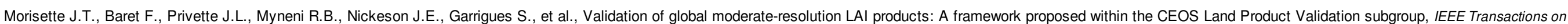
Geoscience and Remote Sensing 44, 2006, 1804-1817.

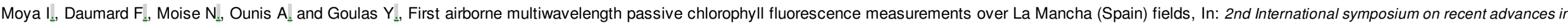
Quantitive quantitative remote sensing 2006, 820-825.

Papageorgiou G-_. $\mathrm{C}_{-}$and Govindjee, Chlorophyll a fluorescence-_- A signature of photosynthesis, 2004, Springer, 818

Pedrós R., Goulas Y., Jacquemoud S., Louis J. and Moya I., FluorMODleaf: A new leaf fluorescence emission model based on the PROSPECT model, Remote Sensing of Environment 114, $2010,155-167$.

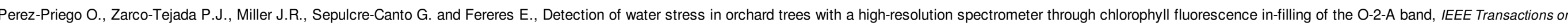
Geoscience and Remote Sensing 43, 2005, 2860-2869.

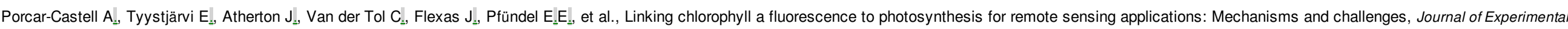
Botany 65 (15), 2014, 4065-4095.

Rautiainen M., Heiskanen J., Eklundh L., Mottus M., Lukes P. and Stenberg P., Ecological applications of physically based remote sensing methods, Scandinavian Journal of Forest Research 25, 2010, 325-339.

Rautiainen M. and Stenberg P., Application of photon recollision probability in coniferous canopy reflectance simulations, Remote Sensing of Environment 96, 2005, 98-107.

Thenkabail P.S., Enclona E.A., Ashton M.S. and Van der Meer B., Accuracy assessments of hyperspectral waveband performance for vegetation analysis applications, Remote Sensing of Environment 91, 2004, 354-376.

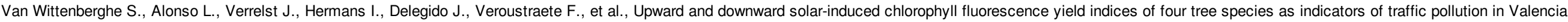
Environmental Pollution 173, 2013, 29-37.

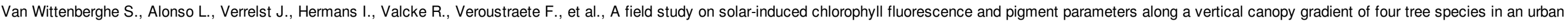
environment, Science of the Total Environment 466-467, 2014, 185-194.

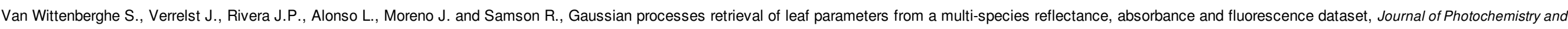
Photobiology B--Biology 134, 2014, 37-48.

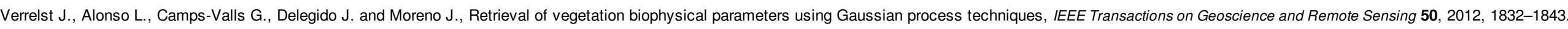

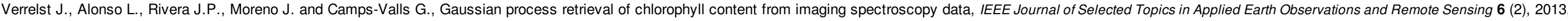
867-874.

Vogelmann T.C. and Han T., Measurement of gradients of absorbed light in spinach leaves from chlorophyll fluorescence profiles, Plant, Cell and Environment 23, 2000, 1303-1311.

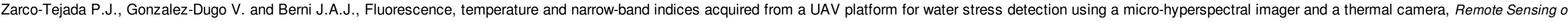
Environment 117, 2012, 322-337. 
Highlights

-When leaves are sunlit from above, Chl fluorescence is emitted upward and downward!

- Downward sun-induced fluorescence (SIF) is mainly emitted in the far-red/NIR

- Leaf architecture plays a role in the partitioning between upward and downward SIF

- Leaf scattering properties are linked to bidirectional leaf SIF

\section{Queries and Answers}

Query:

Please confirm that given names and surnames have been identified correctly.

Answer: The names are correct.

Query:

The citation "Van Wittenberghe et al., 2014a" has been changed to match the author name/date in the reference list. Please check here and in subsequent occurrences, and correct if necessary. Answer: Ok.

Query:

The citation "Van Wittenberghe et al., 2014b" has been changed to match the author name/date in the reference list. Please check here and in subsequent occurrences, and correct if necessary. Answer: Ok, I checked the references. 